\title{
Is Overpopulation a Growth? The Pathology of Permanent Expansion
}

Patricia Vieira

\section{The Growth of the Species, or our Anthropocentric Bias}

Let us begin with a thought experiment. Imagine a species that, after existing for millennia with a relatively stable population, suddenly starts to expand at an increasingly fast pace. This species will appropriate a larger and larger amount of natural resources, thus impoverishing its environment and exhausting its carrying capacity. It will colonize areas that were hitherto the sole domain of other living beings and, in the process, destroy the balance of entire ecosystems and drive many other species to extinction. It will, after a while, transform its habitat beyond recognition, making it poisonous even to its own individuals. How would we judge the development of such a species? Is its multiplication a kind of progress? Would we say that it is flourishing? Do we deem such an increase to be growth?

Our answer to these queries depends very much on the species in question. We could be referring to a plant that, after inhabiting an ecological niche for most of its existence, was carried to and multiplied in various parts of the globe with the aid of human transportation systems. The so-called 'invasive' plants, such as the American and African lantana in Australia or the Asian kudzu in some parts of the United States are good examples of this phenomenon. Without natural mechanisms of control, they spread rapidly in their new environment, deprive native species of their space, and therefore wreak havoc on local flora, fauna, and often on agriculture. Some of these particularly successful plants are classified as 'weeds', and graced with the adjectives 'noxious' or 'injurious' in the areas of the world they have 'invaded', so as to distinguish them from other more benign vegetal forms of life

The Oxford Literary Review 38.1 (2016): 67-83

DOI: 10.3366/olr.2016.0180

(C) Edinburgh University Press

www.euppublishing.com/journal/olr 
that do not share with them such an alarmingly disruptive expansion pattern. The most common response to invasive weeds is to prevent them from taking root, to control their increase once they are in place, and, if possible, to eradicate them from 'colonized' areas. Unbridled growth is, at least in the case of flora, regarded as an evil to be averted and fought at all costs.

Attitudes towards the growth of animals do not differ substantially from our views on plants. Common European mammals like rabbits are considered hugely destructive in some areas to which they were taken through human colonization and where they reproduced exponentially, Australia being, once again, a case in point. Other instances of devastation brought by expanding animal numbers are the well-document damage caused to native fishes by the introduction of the Nile perch in Lake Victoria or the spread of disease-carrying mosquitoes, such as the malaria-inducing anopheles or the yellow fever, dengue and zika aedes mosquito, to different areas of the world. Similarly to what happens in the case of flora, humans tend to treat such out-of-control animal reproduction as a plague to be either circumscribed or, if possible, completely eliminated. From the efforts to limit the populations of cockroaches, rats, pigeons and other perceived pests in our large cities to the attempts to manage outbreaks of mosquitoes in tropical and subtropical areas, the rapid increase of one or a few animal species to the detriment of others is seen as a danger not only for human beings but also for the environment as a whole.

Still, when it comes to a certain kind of animals - human beings we apply criteria to judge population expansion that differ substantially from those used to assess the increase in the number of plants and other animals. There is a widespread belief that humankind is more deserving, or simply superior to other living beings, and therefore has an innate right to keep augmenting in numbers, even to the detriment of other species. Given this implicit assumption, the fact that there are more and more of us, and that the trend does not show signs of abating - the UN estimates that the human population will reach more than 9.7 billion in 2050 and a staggering 11.2 billion in $2100^{1}$ — is generally avoided as a subject of discussion in recent debates about environmental degradation, such as the UN Climate Change Conference that took place in the end of 2015. 
The truism that the earth will literally run out of space for so many of us in a few centuries if our numbers continue to expand at current rates - as Paul Ehrlich put it in the 1960s, given the rate of growth at the time, in 900 years we would need a continuous apartment building many stories high covering the entire planet just to house everybody ${ }^{2}$ - is often brushed aside by environmentalists who espouse the so-called Demographic Transition Theory (DTT), according to which, as societies develop, fertility rates will necessarily drop. While this has certainly proven to be true, even at present the earth would not be able to support the lives of all existing humans if everyone adopted the lifestyle of 'developed' nations such as the United States or those of Europe. ${ }^{3}$ Popular culture, in its turn, has a more escapist approach to the problem of overpopulation. It suggests that, if life on earth becomes unsustainable, we can simply offer other parts of the universe the gift of our presence. A slew of recent Hollywood films, from Christopher Nolan's Interstellar (2014) to Ridley Scott's The Martian (2015), focus on the topic of colonization of different planets, whose resources, one would imagine, we would proceed to plunder following the pattern already established on earth, in order to facilitate our continuously rising population. ${ }^{4}$

Our inability to recognize, let alone tackle, the problem created by an uncontrollable expansion of humans reveals an anthropocentric bias underpinning our idea of growth. While we deem the excessive increase of virtually every other living species as potentially threatening to life as a whole, we seem to accept the incommensurate enlargement of humanity as something neutral or even positive. Significantly, the only exceptions to our condemnation of the unrestrained expansion of flora and fauna are those that cater to our wellbeing: plants and animals consumed as human nourishment, like rice, potatoes, wheat, cows or chickens; those that serve as raw materials, like many trees or certain animals, needed for their hides; or those used as adornments or for recreation, such as flowers or pets, have been actively cultivated, bred, and allowed to multiply beyond their original, modest populations. As a rule of thumb, then, human numbers and those of the plants and animals that contribute to our development never grow too much for our taste. Conversely, the population size of all other beings should be managed and limited when it threatens to get out of hand. 
Our anthropocentric bias when it comes to growth extends not only to the population but also to other areas of human activity that depend on our numbers, such as economic output and consumption. In the case of human beings, we act upon the premiss that larger and more are always better - we envision two birds, More and Better, roosting on the same branch, in Bill McKibben's evocative image.5 The stark contrast between our notion of what healthy non-human and human kinds of growth look like signals a qualitative difference in the very understanding of what it means to grow in various contexts. In the rest of this article, I trace the roots of our views on humanity's growth and address their consequences for thinking about population. I subsequently turn to two alternatives to the dominant model of growth that stem from economic and social theory, namely no-growth (or steady-state) and degrowth, and discuss their impact upon population control. In the last section, I go back to the origins of the concept of growing and consider how this historical background might enrich the current, impoverished idea of growth and inform a renewed reflection on human population.

\section{Growth Ideology}

Judging from what we know based upon verbal accounts and pictorial records, the idea that any aspect of human society, be it the economy or the population, could grow indefinitely is fairly new. ${ }^{6}$ For most of our existence we were persuaded that our lives went on pretty much in the same way as those of our ancestors. Alternatively, in some cultures such as in Ancient Greece or in Ancient Israel, people came to believe that they inhabited a fallen world that followed a Golden Age, as described for instance by Hesiod in his Works and Days, or in the story of the Garden of Eden that we read in the Book of Genesis.

Christianity, an inheritor both of Ancient Greek thought and of Judaism's Messianic tradition, was based upon the premise that salvation would arrive sometime in the future, even if only through divine intervention in the end of times or after death in the kingdom of heaven. But, starting with the Scientific and Industrial Revolutions in Europe, people came to be convinced that improvement might be achieved through human efforts, independent of heavenly intercession. The incremental accumulation of knowledge that formed the bedrock of modern science, the experience that the material conditions of 
life were improving thanks to the easier access to consumer goods that the mechanization of agriculture and industry allowed, and the Enlightenment's confidence in the power of reason to achieve social and political change, persuaded Western populations that human history was on a linear path towards a better future, in which each generation could expect to live better than the preceding one. ${ }^{7}$

While progress was firmly established as one of the pillars of Western modernity's worldview by the nineteenth century, the idea that unending economic and population growth were desirable, or even possible, required longer to take root. The concept of progress encompassed a whole array of issues, including not only material wellbeing but also social stability, political freedom, cultural and artistic advancement, and so on (Victor, 8). It is unclear whether the founders of modern economics, or political economy as it was then known, saw the increase in economic activity in their lifetimes as an isolated event or as a trend that would continue indefinitely (McKibben, 6). John Stuart Mill, for one, was averse to continued economic and population growth, writing in his Principles of Political Economy that, ' $[\mathrm{i}] \mathrm{f}$ the earth must lose that great portion of its pleasantness which it owes to things that the unlimited increase of wealth and population would extirpate from it, for the mere purpose of enabling it to support a larger, but not a better or a happier population, I sincerely hope (...) that they will be content to be stationary. ${ }^{8}$ Similarly, Thomas Malthus's predictions about the grim consequences of unchecked population growth are wellknown.

We had to wait until the twentieth-century for permanent growth to become a key component of progress. According to Peter Victor, the commitment to growth was, at first, an offshoot of governments' goal to keep their citizens working. Production had to be constantly increased in order to provide employment to an expanding workforce and growth was therefore regarded more as means to create job opportunities than as an end in itself (13). By the 1950s, however, growth had become a key economic priority, as $\mathrm{H}$. W. Arndt argues in his book The Rise and Fall of Economic Growth. It was viewed not only as a solution for the problem of unemployment but also as a means to guarantee continued improvement in living standards within a given society, as well as to ensure a tactical advantage in comparison with the economic performance of other nations. ${ }^{9}$ The final connexion between 
growth and society's wellbeing was forged in the neo-liberal turn of the 1980s. In a de-regulated market in which societal concerns are mostly sidelined, economic growth - generally measured in terms of GDP became the one yardstick to determine success. By now, growth is well-established as the paramount economic precept that guarantees prosperity (McKibben, 9-10)

As the economic growth ideology was cemented with the introduction of neo-liberal policies, the issue of population control receded into the background. Historically, the human population was characterized by high birth and mortality rates but, with the emergence of modern medicine and sanitation, mortality dropped rapidly. ${ }^{10}$ The birth rate, albeit lower than it used to be worldwide, ensured a steady population increase with our numbers more than doubling between the mid-1800s and the 1950s. Coinciding with the emergence of the environmental movement in the 1960s, debate about the ideal size of the population and the best ways to reduce it became part of public and political discussion both on the left and on the right. President Nixon, for instance, warned Congress of the dangers inherent in the rapid growth of the American population, including faltering social services and the depletion of natural resources (Coole 198). ${ }^{11}$

Yet, by the 1980s, neo-liberal and socially conservative demographic revisionists, grounded in the Demographic Transition Theory (DTT), were promoting population skepticism and pushing population concerns out of the sphere of public debate. Diana Coole defines DTT as one of the great narratives of modernization and uncovers the ideological stakes in eliminating reflections on overpopulation by resorting to this grand narrative (203). For neo-liberal policy makers, the attempt to guide people's reproduction smacks of leftwing statism and curtails their reproductive freedom, in the same way that regulations prevent the adequate functioning of the economy. The invisible hand of the market is presented as a solution for the population problem, since economic freedom necessarily leads to rational behaviour, which includes making the right reproductive choices (Coole, 205).

Some demographic revisionists go even further and argue that population growth is neutral or even beneficial for the environment, because more people mean increasing opportunities for technological innovation, which, in turn, might lead to novel breakthroughs in 
sustainable development (Coole, 205). Perhaps the next child will be a new Albert Einstein, so the reasoning goes. More likely, however, is a scenario where that child will be an undernourished slum dweller living on the outskirts of one of the world's megalopolises, or a climate refugee fleeing flooding or drought. Needless to say, the world population is already stretching the earth's limits with the current more than 7 billion people. Our continued growth is bound to make the situation deteriorate ever further and at a faster pace.

The link between neo-liberal proponents of economic and population growth is not fortuitous. If we agree with Zygmunt Bauman, according to whom we have entered a stage of 'liquid modernity', predicated primarily on consumption, rather than production - Bauman calls ours a 'liquid' 'society of consumers', which differs from the previous 'solid' 'society of producers' in that the latter focused on the production and appropriation of goods as a longterm effort, while the former thrives on the consumption and rapid disposal of commodities, to the point where human beings themselves become commodified ${ }^{12}$ - we soon realise that growth is an inescapable part of such a social arrangement. Consumption creates the need for more commodities that, in turn, require more consumers to purchase them. The population needs to increase to maintain economic growth and the economy has to expand so that the growing population keeps its living standards, the two expansionist trends feeding upon one another in a vicious circle from which there is no escape.

\section{No-Growth and Degrowth}

Given the increasingly apparent nefarious effects of permanent economic and population increase on the environment, as well as the blatant impossibility of continuous growth in the context of a finite planet, economists and social theorists have come up with proposals to curb expansion and to adjust human societies to the earth's limits. Studies such as Ezra Mishan's The Costs of Economic Growth (1967), Nicholas Georgescu-Roegen's The Entropy Law and the Economic Process (1971), the Limits to Growth report by Donella Meadows et al. (1972), E. F. Schumacher's Small is Beautiful (1973), and Herman Daly's Steady-State Economics (1977), to name but a few foundational texts, have criticized the growth ideology that underpins modern thought and shown that it is divorced from the interests of the majority 
of the people. The degrowth movement that emerged in several European countries - especially in France, Italy and Belgium - in the last two decades had its roots in this critique of growth, which it expanded to form a wider social movement. ${ }^{13}$ The proponents of degrowth in France, for instance, have created a monthly magazine (La Décroissance), a political party (Parti pour la Décroissance), as well as a plethora of other discussion groups and activities (Fournier, 531; 533). ${ }^{14}$

Opponents of the growth ideology have been unanimous in emphasising that, beyond its destructive environmental consequences, an expanding economy has failed to increase people's quality of life. Tim Jackson points out in his Prosperity without Growth that, after a GDP of about US\$15,000 per capita, life satisfaction scores no longer correlate to increases in GDP. ${ }^{15}$ In other words, life satisfaction only augments with more material goods and services up to the point when basic necessities are met. After that, our happiness depends on how we think that we fare when compared to other members of our society. ${ }^{16}$ Similarly, other indications of prosperity such as life expectancy, rates of infant mortality or participation in education, do not improve after a certain threshold of material wealth, with countries like Chile, Cuba and the United States showing similar results in all three categories (Jackson, 56-9). While there is a strong case for continued economic growth in the poorest countries until they catch up with the richer ones, Jackson concludes, the growth of a developed nation will have little or no impact in that society's prosperity (41).

In light of the disconnect between growth and prosperity, many advocate for a so-called steady-state economy in which there would be either no growth or just a residual one. Following in the footsteps of Herman Daly, Douglas Booth delineated a steady-state proposal that would limit production - both in terms of energy/matter throughput and, especially, in terms of emissions - to levels that could be absorbed by the environment and sustained in the long run. ${ }^{17}$ For Booth, such change would require a profound transformation of current economic practices. As Joseph Schumpeter has argued, capitalist economies, based upon profit and capital accumulation, depend upon the continuous creation of new consumer goods that render the older ones obsolete in a process of 'creative destruction', growth being, therefore, an inalienable feature of such economic systems (Booth, 11). Bill 
McKibben sums it up when he writes that, 'under present arrangements any faltering of growth leads quickly to misery: to recession and all its hardships' (10). Booth suggests a number of measures that could be adopted to wean our economy from growth, including, on the macroeconomic level, an incomes policy, an expanded government sector and a reduction in the workweek, together with, on the microeconomic level, greater economic democracy in the form of producer cooperatives (155).

While Booth does not focus on overpopulation, he recognizes that 'rapid population growth will exacerbate the problem [of moving towards a steady-state economy] and slow population growth or population stability will mitigate it' (152). Similarly, Jackson highlights that the goal of having a prosperous society needs to take population into account. He writes that our prosperity is limited by "the finite nature of the ecological resources within which life on earth is possible" and "the scale of the global population' (45). A steady population is therefore a requirement for achieving a lasting prosperity without economic growth.

Unlike steady-state economy proponents, who focus on the pragmatic aspects of establishing a system that does not depend on growth, the advocates of degrowth give primacy to the cultural features involved in such a shift. Serge Latouche, one of the leaders of the degrowth movement in France, calls in his book Farewell to Growth for a 'cultural revolution (...) that reestablishes politics on a new basis'. ${ }^{18}$ For Latouche, 'the de-growth society project is eminently revolutionary', since it does not simply aim to reform pre-existing structures but, rather, to undertake a complete overhaul of social arrangements that would be grounded upon different principles (66). The economist model of society, predicated on efficiency, performance, profitability, flexibility, and so on, should undergo critical scrutiny (55). To put it differently, it is necessary not only to suggest alternative economic models, as the defenders of a steady-state economy have done, but, first and foremost, to question the centrality of economic determinations in our lives, to subordinate the economy to political objectives, and to place it once again at the service of people's wellbeing (Fournier, 533).

Some of the concrete measures put forth by Latouche coincide with the ones suggested by steady-state economists, including the 
regionalization of the economy; the internalization of externalities, including the environmental costs of producing, advertising and transporting commodities; re-using and recycling products; and a reduction of the workweek. But Latouche also underlines the need for greater altruism, cooperation and conviviality, in a society in which the 'pleasure of leisure and the ethos of play should replace the obsession with work' (34). It is such a 'change in the imaginary' that will ultimately lead to the creation of the 'fertile,' 'concrete utopia' of degrowth $(31 ; 76)$.

While degrowth could only be fully implemented in a post-capitalist society, Latouche is quick to point out that productivism permeated both capitalist and historically socialist countries like the USSR and China, which failed to take ecological issues into account (89). Moving away from both of these social organisations, Latouche considers degrowth to be not a return to the past - a going back to the Stone Age, as he puts it (69) — but, rather, a way to go 'beyond modernity' and its attendant ideology of unlimited progress, development, and growth. A degrowth society is thus, on the one hand, 'fundamentally anticapitalist' in its rejection of increased productivity, consumption and competitiveness (91) and, on the other hand, a transformed version of classical socialism: it is an 'eco-socialism' (92) that highlights the importance of social bonds and, at the same time, strives to keep the economy in tune with the environment.

Supporters of the degrowth movement tend to be dismissive of population control as a means to ameliorate environmental problems. Latouche finds population reduction to be a 'false' and 'lazy' solution espoused by conservative politicians who are interested in maintaining the status quo of economic growth (25). He is critical of efforts to limit population expansion for focusing on developing countries, which are the ones that consume less of the planet's resources. Such an approach smacks of racism and he accuses it of perpetuating the mechanistic understanding of societal development characteristic of the growth ideology (25-27). More important than world population growth is, for Latouche, the equitable distribution of existing resources (29). He believes that once a degrowth society which curbs excess and overconsumption is in place, the problem of overpopulation can easily be tackled (28). 
The steady-state economy proponents and the members of the degrowth movement have the merit of putting into question the current growth ideology and of outlining social forms of organization free from the need to expand continuously. As degrowth defenders have noticed, one of the failures of steady-state proposals is that they focus almost exclusively on economic reform, sidelining matters like cultural habits and expectations that play a key role in our societies' addiction to growth. The degrowth movement does offer a more encompassing view of the social transformation required to abandon the growth ideology. However, it fails to recognize that economic and population increase go hand-in-hand. What is lacking in both approaches is an in-depth reflection on what it means to grow. In the final section of this article I undertake an archaeology of the idea of growth and suggest that, rather than no-growth or degrowth, we need to devise a different kind of human growth, more in tune with that of the other living beings with whom we share the planet.

\section{Another Growth is Possible}

In our post-modern societies, growth is commonly understood mathematically as quantitative increase that can potentially continue ad infinitum. In this reified form, growth has become pathological — it has turned into a growth - , since any ever-expanding living entity is necessarily doomed to (self-)annihilation. By simply turning the tables and favouring either a steady, little or no-growth, state, or degrowth, the approaches discussed in the previous section eschew the deeper issue of understanding the meaning of growth and of considering the possibility of a different kind of growing.

In Western thought, the idea of growth is inextricably linked to that of nature, or phusis, the Ancient Greek word that was translated as natura into Latin. As Gerard Naddaf explains in his study on The Greek Concept of Nature, the term phusis is derived from the verb phuo-phuomai, which, in turn, is thought to go back to the IndoEuropean root ${ }^{*} b h \bar{u}$, meaning 'to grow, to produce, to develop' (12). ${ }^{19}$ Phusis, like all other action nouns, results from the addition of the suffix $-i s$ to a verb and corresponds to an abstraction of the process described by the verb in its objective realization. The fundamental meaning of phusis, then, is 'the whole process of growth of a thing from birth to maturity' (12). It follows that a being's nature, in Ancient 
Greek, referred to the ways in which it developed from inception to its full capabilities, growth implying a qualitative evolution, rather than mathematical multiplication. Significantly, the Ancient Greek word for 'plant,' phutón, derives from the same verb as phusis. Plants were considered to be the growing beings par excellence and the prototype for all other creatures, another meaning of the word phutón.

When phusis was translated into Latin it lost its connexion to growth, since the noun natura derives from the verb nascor, 'to be born'. But the Ancient Greek idea of growing as the unfolding of a living being's, and especially a plant's, potentiality lives on in the English word 'growth', as well as in its equivalent in most Romance languages - croissance in French, crecimiento in Spanish, or crescita in Italian, for instance. In all of these cases, the term for 'growth' goes back to agriculture and cultivation, to the cycles of sowing and harvesting. It is therefore not surprising that the name for the Latin goddess of agriculture, Ceres, shares its etymology with the Latin verb for growing, crescere.

This excursus into the roots of the term 'growth' in various IndoEuropean languages reveals the link between the idea of growing and the concept of nature, viewed as a set of a being's innermost possibilities that unfold in the course of its development. The common model for 'growth' seems to have been the lives of plants and, by extension, the rhythms of crop cultivation and agriculture. The corollary of such a notion of growing is that it would necessarily incorporate a downturn or decline, in the same way that the nature of all beings encompasses both a movement of expansion and one of decadence, demise and, eventually, transformation into something else. The analogy with plants is pertinent here: they are born out of a seed, develop to full maturity, flower, give fruit and, in the end, die, leaving behind their seeds that will become future plants. The geometrical representation of this understanding of growth would not be a line that moves towards infinity but, rather, a cycle or, at most, a spiral, whose circular motion is subtly transformed and, perhaps, improved, with each revolution.

The anonymous article 'Personal Growth' reflects upon the notion of growing along similar lines. Through an analysis of texts by Hegel, Heidegger and Bataille, the author emphasizes both the link between plant life and growth, and the decay that, like a poison, 'infects' every growing being. ${ }^{20}$ There is "[n]o being without growth, no growth without outgrowth, no outgrowth without decay, infection and death" 
(149), a statement that renders growth coterminous with life, in its manifold manifestations. This is the thrust of Heidegger's discussion of phusis as the emergence or appearance of Being — an unfolding or growth that goes beyond the techno-scientific understanding of physics and nature in modernity (140-1).

Going back to the beginning of this article, we noted a discrepancy in the way we regard the growth of non-humans and that of our own species. It turns out that our understanding of the growth of other living beings is more in tune with the original meaning of the word. We consider that flora and fauna should respect their natural boundaries when it comes to their development. If these are overcome-due to different circumstances, most often the transplantation to a foreign environment - we attempt to conduct the specific plant or animal back to the limits we deem appropriate for it to express its own nature.

When evaluating human development, conversely, we have abandoned the qualitative underpinnings of our considerations of plant and animal growth. The historical circumstances briefly alluded to in the second section of this article, including the Scientific and Industrial Revolutions and the advent of capitalism as an hegemonic form of economic organization, led us to see human growth as completely divorced from all constraints. Under present circumstances, the mathematical increment that goes by the name of human 'economic and population growth' is qualitatively different from what we consider to be the growth of other species, to the extent that we should perhaps call it something else, such as 'increase'. Be this as it may, the fissure at the heart of our current concept of growth bespeaks a deeper gap between human beings and their surroundings, whereby we consider ourselves to be apart from and, to a certain extent, in opposition to the environment that supports our existence. If our expansion, both in numbers and in terms of economic production, has become a planetary growth, it is perhaps time to suture the rift in our idea of growing and reclaim the origins of the term in order to realise that another growth is possible. What would a qualitative model of growth look like? How could human growth become more plant-like, attuned to the cycles of flourishing, fructification and decay? And what would the implications of this environmentally attuned growth be for tackling the population problem? 
The bond between nature and growing, encapsulated in the Ancient Greek word phusis, offers a number of clues for reconfiguring human growth. The first consequence of a qualitative understanding of growth is that our emphasis on continuous expansion needs to be discarded. Expansion has historically been the foundation for various levels of human activity: geographical expansion drove human migrations for millennia, from the great relocations of the sapiens group of hominids from Africa to various parts of the globe to the European conquest of America from the sixteenth century onwards; economic and population expansion have been closely tied to geographical conquest, colonialism and globalization being the modern expressions of this movement. While expansion might have made sense in the context of an open, unknown world, it is certainly an outdated notion today. We have resorted in late capitalist societies to an uninterrupted flow of production, creating increasing amounts of commodities as a means to replace the novelty afforded by unknown lands. Having run out of fresh geographical spaces, we focus on new products and gadgets as a way to conquer different segments of the market. In the same way as an increasing population was needed for geographical expansion, more consumers are required to absorb new commodities, in an unending race between the economy and population that has led to environmental disaster. But, as physicists tell us, nothing expands forever, not even the universe, let alone the human race. A renewed concept of growth should incorporate moments of expansion and contraction, enlargement and diminishment, as part of humankind's expression of its potential as a species. To grow means to accept and welcome such fluctuations that will, in time, result in a diastolic/systolic balance governing both the economy and population.

But leaving permanent expansion behind is just the first, more superficial step in reconfiguring growth, in that it remains beholden to the logic of numerical increases and decreases. A second, more consequential issue is that of considering the development of humanity's possibilities. It suffices to contemplate images of extremely polluted cities like Beijing on a smoggy winter day, when inhabitants are either forced to stay at home or resort to wearing facemasks, to realise that our lifestyle is seriously threatening our collective ability for flourishing. A growth attuned to the environment and its cycles recognizes that the process of growing needs to attend to 
the development of various human yearnings, including not only the means to meet basic needs but also leisure, creative engagement with our surroundings and the enjoyment of the natural environment. All of these are being threatened by overproduction and overpopulation.

A final offshoot of a qualitative consideration of human growth is the acceptance of self-imposed limitations. When humanity ignores that its quantitative increase is bound to run against environmental constraints it embarks onto a course of action that is both too natural and not natural enough. By disregarding restrictions to economic and population enlargement, humans behave in the same way as other living beings, whose growth is controlled by environmental boundaries, such as the availability of food or the number of predators. In the course of recent human history, we have faced several of these natural limits, including food shortages or highly contagious viral diseases. But by delivering ourselves to natural phenomena we ignore our ability to make choices about various aspects of our individual and social existence; we behave as though we were not the product of culture and were, instead, completely beholden to natural cycles. When we fail to consciously decide on limits for our collective growth, leaving the environment to force those upon us, we are, in fact, not being natural enough; in other words, we are neglecting to act based upon our reflexive nature. A growth that expresses the unfolding humanity's possibilities would have to take our capacity to let our thoughts shape our actions into account. Setting boundaries for economic and population growth and, more importantly, deciding upon what growing really means, is the true hallmark of respect for human nature.

What I am advocating here is not a naturalized view of humans, who should go back to the fold of nature in order to overcome the overpopulation crisis. As plants grow and decay according to their own being, so should humans unfold in attunement to theirs, which means embracing a series of cultural reflections, mediations, norms and limitations that characterize humanity's being in the world. Population growth and efforts at population control reveal the complex imbrication of nature and culture that fashions human sexuality, procreation and considerations on filiation, family size, environmental protection and the possibilities for growing. A truly human growth, then, would not bring us closer to but, on the contrary, require a move away from natural constraints by reflecting upon and defining limits to 
human reproduction. By burrowing deeper into our humanness, that is to say, by welcoming the inevitability of our separation from nature, we paradoxically come back full circle to phusis as plant growth, with restraints, decay and death embedded in the very process of flourishing. But ours would be a Hegelian return, in full conscience (Gewissen) of our finitude and that of life itself.

\section{Notes}

1 'Probabilistic Population Projections based upon the World Population Prospects: The 2015 Revision' (United Nations) http:/lesa.un.org/unpd/wpp/ Download/Probabilistic/Population/, consulted 18 February 2016 at $4.19 \mathrm{pm}$.

2 Paul Ehrlich, The Population Bomb (New York, Ballantine Books, 1978), 4.

3 We would need about six planets if every person on earth consumed the same as the average American.

${ }^{4}$ As Paul Ehrlich puts it, '[i]f you still want to hope for the stars, just remember that, at the current growth rate, in a few thousand years everything in the visible universe would be converted into people, and the ball of people would be expanding with the speed of light!' (6). Sarah Conly makes a similar point when she writes about colonizing other planets as a possible solution to the earth's overpopulation: 'Sure, it is possible that something extraordinary will happen to prevent that [human selfdestruction because of overpopulation]: that we will colonize other planets, say, before we have run out of fuel or water. At present, though, there's no other livable planet in sight, so we pretty much need to plan around staying on this one. And on this earth, unlimited population growth would be catastrophic.' Sarah Conly, One Child: Do we Have a Right to More? (New York, Oxford University Press, 2016), 27.

5 Bill McKibben, Deep Economy: Economics as if the World Mattered (Oxford, One World, 2007), 1. McKibben's point is that, even though More and Better have long lived side by side, Better has now left to make her nest elsewhere. We are thus left to choose between having more or living better lives (1).

${ }^{6}$ Peter A. Victor. Managing without Growth: Slower by Design, not Disaster (Cheltenham, UK, Northampton, MA, USA, Edward Elgar, 2008), 5.

7 For an in-depth discussion of the idea of progress, see Sidney Pollard, The Idea of Progress: History and Society (New York, Basic Books Publishers, 1968).

8 John Stuart Mill, Principles of Political Economy (Online Library of Liberty), http://lf-oll.s3.amazonaws.com/titles/101/Mill_0199_EBk_v6.0.pdf, consulted 18 February, 2016, 4.42pm. 
${ }^{9}$ H. W. Arndt, The Rise and Fall of Economic Growth, (Sydney, Longman Sheshire, 1978), $73 \mathrm{ff}$.

10 The high birth rate prevalent throughout most of human history is attributable to a number of biological and cultural factors. A high birth rate was necessary to counter the high mortality, especially among infants, that plagued humanity for a long stretch of our existence; without a high birth rate, we would have simply become extinct. Furthermore, having many children was often economically advantageous in pre-modern cultures, as these could help the family in agricultural and other chores. Finally, having many children was also a sign of family power and of virility in many traditional cultures.

11 Diana Coole, 'Too Many Bodies? The Return and Disavowal of the Population Question', Environmental Politics 22.2 (2013), 195-215.

${ }_{12}$ Zygmunt Bauman, Consuming Life (Cambridge, UK, and Malden, MA, Polity Press, 2007), 29-31.

13 The French word for 'degrowth,' 'décroissance' originates in the French translation of the term in Georgescu-Roegen's The Entropy Law and the Economic Process. See Valérie Fournier, 'Escaping from the Economy: The Politics of Degrowth', International Journal of Sociology and Social Policy. 28.11/12 (2008), 531.

${ }^{14}$ Valérie Fournier, 'Escaping from the Economy: The Politics of Degrowth', International Journal of Sociology and Social Policy 28.11/12 (2008), 528-45.

15 Tim Jackson, Prosperity without Growth. Economics for a Finite Planet (London and Sterling, VA, Earthscan, 2009), 40.

16 We evaluate our perceived happiness comparatively to how we deem other members of our society to be doing. How we compare to others depends, in turn, on the level of social inequality. Bill McKibben argues that a growth economy has led to increasing inequality, which, in turn, has made us less and less happy (11-14).

${ }^{17}$ Douglas E. Booth, The Environmental Consequences of Growth: Steady-State Economics as an Alternative to Ecological Decline (London and New York, Routledge, 1998), 132.

18 Serge Latouche, Farewell to Growth, translated by David Macey (Cambridge, UK, and Malden, USA, Polity Press, 2009), 32.

19 Gerard Naddaf, The Greek Concept of Nature (Albany, State University of New York Press, 2005), 12.

20 'Personal Growth', Oxford Literary Review, 23 (July 2001), 137-52 [142]. 